\title{
Development of Bridged Nucleic Acid Analogues for Antigene Technology
}

\author{
Satoshi OBIKA \\ Graduate School of Pharmaceutical Sciences, Osaka University; 1-6 Yamadaoka, Suita, Osaka 565-0871, Japan. \\ Received July 30, 2004
}

\begin{abstract}
In the last decade, increased efforts have been directed toward the development of oligonucleotide-based technologies for genome analyses, diagnostics, or therapeutics. Among them, an antigene strategy is one promising technology to regulate gene expression in living cells. Stable triplex formation between the triplex-forming oligonucleotide (TFO) and the target double-stranded DNA (dsDNA) is fundamental to the antigene strategy. However, there are two major drawbacks in triplex formation by a natural TFO: low stability of the triplex and limitations of the target DNA sequence. To overcome these problems, we have developed various bridged nucleic acids (BNAs), and found that the $2^{\prime}, 4^{\prime}$-BNA modification of oligonucleotides strongly promotes parallel motif triplex formation under physiological conditions. Some nucleobase analogues to extend the target DNA sequence were designed, synthesized, and introduced into the $2^{\prime}, 4^{\prime}$-BNA structure. The obtained $2^{\prime}, 4^{\prime}$-BNA derivatives with unnatural nucleobases effectively recognized a pyrimidine-purine interruption in the target dsDNA. Some other examples of nucleic acid analogues for stable triplex formation and extension of the target DNA sequence are also summarized.
\end{abstract}

Key words nucleic acid analogue; triplex; antigene; sugar conformation; bridged nucleic acid; locked nucleic acid

\section{Introduction}

In April 2004, a joint proclamation on the completion of the Human Genome Project was made by the heads of government of six countries. The completion of the human genome sequence that has approximately three billion base pairs will effect a revolution in biomedical sciences and related industries. In particular, tailor-made medications, molecular targeted therapies, and genetic medicines based on human genomic information are attracting much attention worldwide. To establish new technologies that will be the fundamentals of various medications and industries in the post-genome era, we have been studying chemical synthesis of artificial nucleic acid analogues. An antigene strategy is one promising technology to regulate gene expression (Fig. 1). In a living cell, genetic information is transferred from double-stranded DNA (dsDNA) to mRNA during transcription and then from mRNA to protein during translation. In the flow of genetic information, the antigene technology inhibits the transcription step by using an oligonucleotide, while the antisense strategy blocks the translation step (Fig. 1). In the antigene strategy, an oligonucleotide hybridizes with dsDNA to form a triplex structure and inhibit the binding of a transcription factor to dsDNA. Eventually, the flow of genetic information is stopped at the transcription step. However, there are some technical problems in the formation of a stable triplex. To overcome the problems, development of novel and chemically modified oligonucleotides is required. ${ }^{1)}$ Furthermore, highly functional oligonucleotide analogues will provide new methodologies not only for blocking genetic information but also for stimu- lating gene expression ${ }^{2)}$ and inducing or repairing genetic mutations. ${ }^{3)}$ In addition, nucleic acids and their analogues will play important roles in many post-genome technologies.

Nucleic acids consist of three parts: a nucleobase, a sugar, and a phosphodiester backbone (Fig. 2). In DNA and RNA, there are five nucleobases: adenine $(A)$, guanine $(G)$, cytosine $(\mathrm{C})$, thymine $(\mathrm{T})$, and uracil $(\mathrm{U})$. Adenine and guanine are called purines $(\mathrm{Pu})$, and cytosine, thymine, and uracil are called pyrimidines (Py). The sugar observed in nucleic acids is a five-membered pentose sugar. The pentose in RNA is ribofuranose and that in DNA is $2^{\prime}$-deoxyribofuranose. The nucleobase attaches to the pentose sugar at the $\mathrm{C} 1^{\prime}$ position to form a nucleoside. The nucleosides are simultaneously linked via a phosphodiester linkage between the 5'- and $3^{\prime}$ hydroxy groups. Among these parts of nucleic acids, we have focused on the sugar moiety. In general, the furanose ring in the sugar moiety of nucleic acids is not planar. ${ }^{4)}$ The furanose ring in nucleosides or single-stranded nucleic acids has conformational flexibility and it is in equilibrium between various conformations. When a nucleic acid forms a duplex or a triplex, however, the conformational freedom is drastically restricted. Thus the formation of a duplex or triplex is entropically unfavorable. To prevent the loss of entropy, preorganization of the sugar conformation in a suitable form would be a promising strategy. Based on this concept, various nucleic acid analogues have been proposed and some have been developed. ${ }^{5,6)}$ The bicyclo-DNA ${ }^{7-9)}$ developed by the group of Leumann et al. has a bicyclic sugar moiety to restrict the conformational flexibility of the furanose ring and the backbone of nucleic acids (Fig. 3). Although the bicyclo- 
DNA shows only moderate triplex-forming ability, it is a pioneering result in this field and has had considerable effect on subsequent related research.

On the other hand, we have designed and synthesized various novel bridged nucleic acids (BNAs) to develop an ideal antisense oligonucleotide. ${ }^{10-12)}$ The target molecule in the antisense strategy is RNA, the sugar conformation of

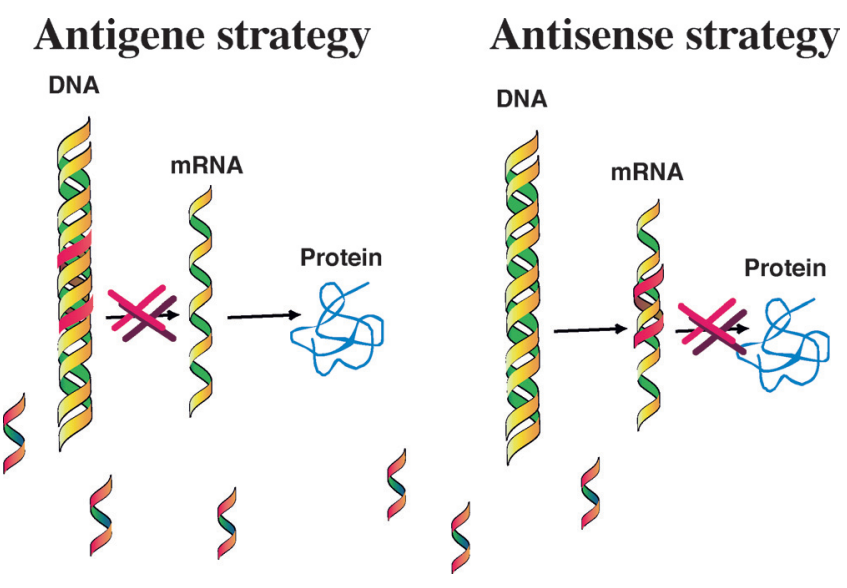

Fig. 1. Schematic Representation of Antigene and Antisense Strategies
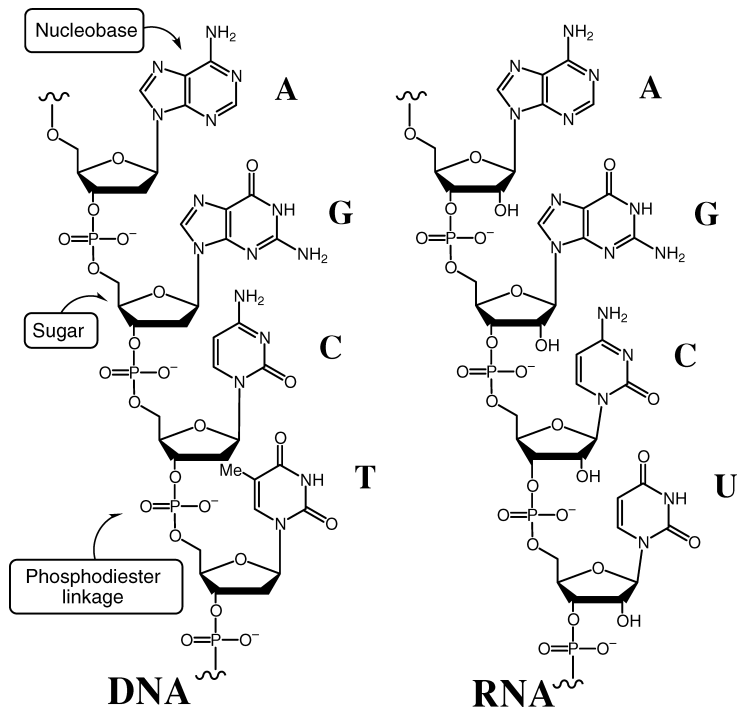

Fig. 2. Structures of DNA and RNA which is predominantly the $\mathrm{N}$ type in solution, and eventually the duplex consisting of RNA prefers to form an A-type helical structure (Fig. 4) ${ }^{4}{ }^{4}$ Therefore restriction of the sugar conformation to the $\mathrm{N}$ type is likely promising for the development a nucleic acid analogue with high binding affinity to its RNA complement. We designed a nucleoside analogue with a methylene bridge between the $\mathrm{O} 2^{\prime}$ and $\mathrm{C}^{\prime}$ ' atoms and successfully achieved the first synthesis of the bridged nucleic acid analogue, $2^{\prime}, 4^{\prime}$-BNA, the sugar conformation of which is completely restricted to the $\mathrm{N}$ type (Fig. 5). ${ }^{13)}$ Oligonucleotides containing the 2',4'-BNA monomer(s)

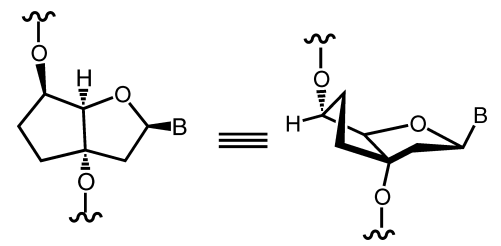

Fig. 3. Structure of the Byciclo-DNA
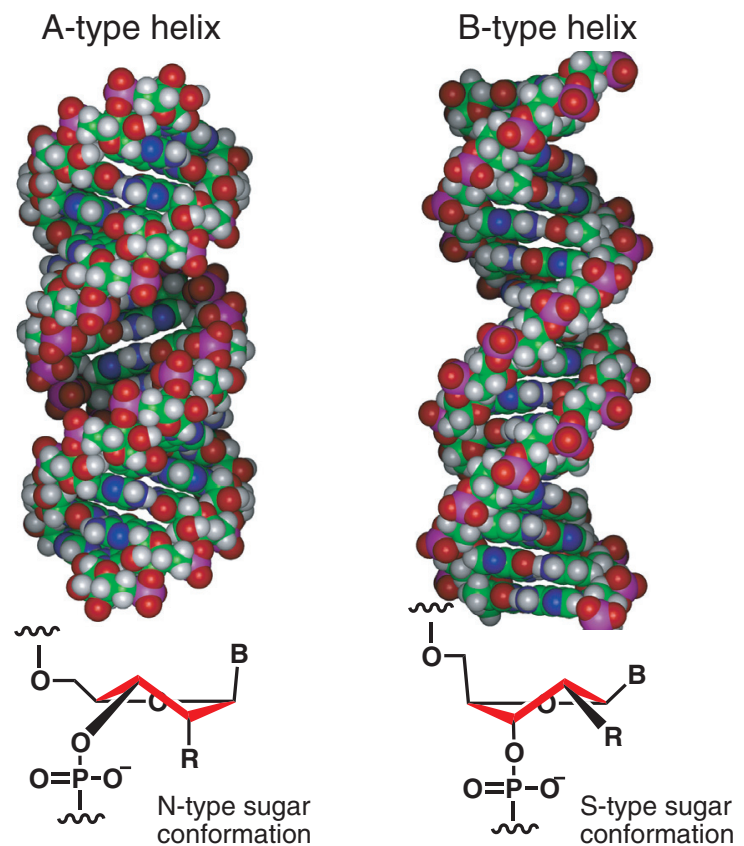

Fig. 4. Illustrations of A-Type Helical Structure and N-Form Sugar Conformation (Left), and B-Type Helix and S-Form Sugar Conformation (Right)

Satoshi Obika was born in Takamatsu, Kagawa, Japan on July 31, 1967. He graduated with a B.S. degree in Pharmaceutical Sciences from Osaka University in 1990. In 1992 he obtained his M.S. degree from Osaka University, where he studied the synthesis of chiral NADH model compounds under the direction of Professor Takeshi Imanishi. That same year he began his career at Osaka University. In 1998 he earned his Ph.D. He received the Pharmaceutical Society of Japan Kinki Branch Award for Young Scientists in 1999 and the Pharmaceutical Society of Japan Award for Young Scientists in 2004.

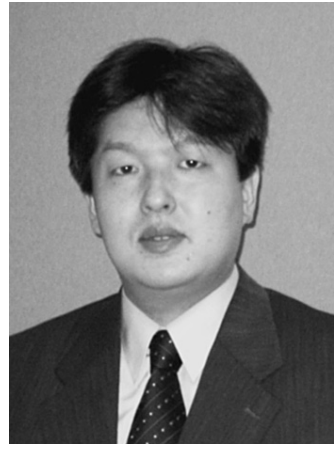

Satoshi Obika 

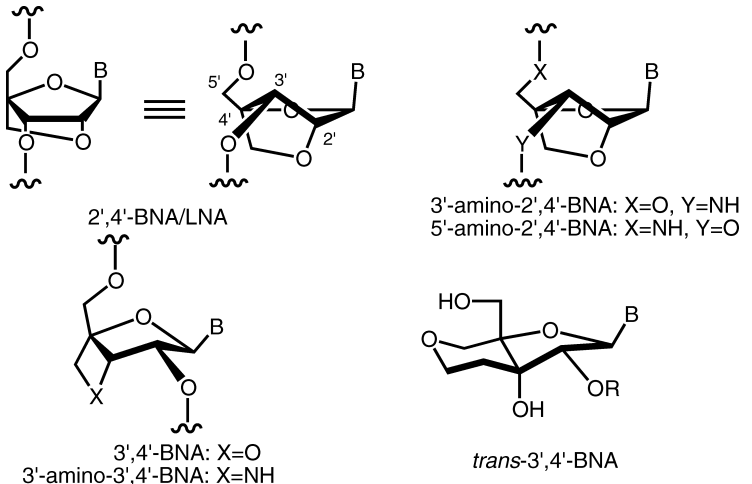

Fig. 5. Structures of $2^{\prime}, 4^{\prime}-\mathrm{BNA} / \mathrm{LNA}$ and Other BNA Families

showed unprecedentedly high hybridization ability with RNA complements. ${ }^{14)}$ In addition, other BNAs have been designed and synthesized (Fig. 5). ${ }^{15-24)}$ Each BNA has its own sugar conformation and shows unique and interesting properties when it is incorporated into oligonucleotides. Among these BNAs, 2', 4'-BNA was independently synthesized by the group of Wengel et al. immediately after our first report, ${ }^{25-29)}$ and it is called a locked nucleic acid (LNA) and is now commercially available. ${ }^{30)}$ The design and synthesis of BNAs (especially $2^{\prime}, 4^{\prime}$-BNA/LNA) have been summarized, ${ }^{10-12}$ ) and some properties such as the duplex-forming ability of $2^{\prime}, 4^{\prime}$-BNA/LNA were also reviewed by our ${ }^{10-12)}$ and other groups. ${ }^{28,29,31)}$ In this account, I focus on the triplex-forming oligonucleotide (TFO) that is fundamental to the antigene strategy and describe our attempts to develop nucleic acid analogues for ideal and practical TFOs.

\section{Background of the Triplex}

The fact that nucleic acid can form a triplex structure was observed in $1957,{ }^{32,33)}$ and the mode of nucleobase triads was experimentally determined by Hoogsteen. ${ }^{34,35)}$ It was revealed from the following studies that the triplexes can be divided into two types: parallel and antiparallel. ${ }^{36)}$ In the parallel motif triplex, the third strand is a homopyrimidine sequence, and the third strand and the Pu strand of the target duplex are in parallel orientation. The base triads form Hoogsteen hydrogen bondings in the parallel motif triplex (Fig. 6). On the other hand, the antiparallel-type triplex has the third strand with a homopurine sequence, and the third strand and the Py strand of the duplex are in antiparallel orientation. The base triads have reverse-Hoogsteen hydrogen bondings (Fig. 6). Generally, triplex formation has some drawbacks compared with duplex formation. First, to form a stable triplex, a homopurine-homopyrimidine tract is required in the target duplex. Second, both Hoogsteen and reverse-Hoogsteen triads have only two hydrogen bondings, while the Watson-Crick base pairs have two or three hydrogen bondings. This is one reason for the low stability of the triplex structure. In addition, the cytosine nucleobase in a parallel motif TFO must be protonated at its N3 position to form a stable nucleobase triad $\mathrm{C}^{+} * \mathrm{GC}$ (in which $*$ means Hoogsteen bonds), which means that the stability of a parallel motif triplex drastically decreases under neutral or basic conditions although it is sufficiently stable under acidic conditions. An antiparallel motif triplex does not show such $\mathrm{pH}$-dependent effects; however, the antiparallel motif TFO sometimes forms
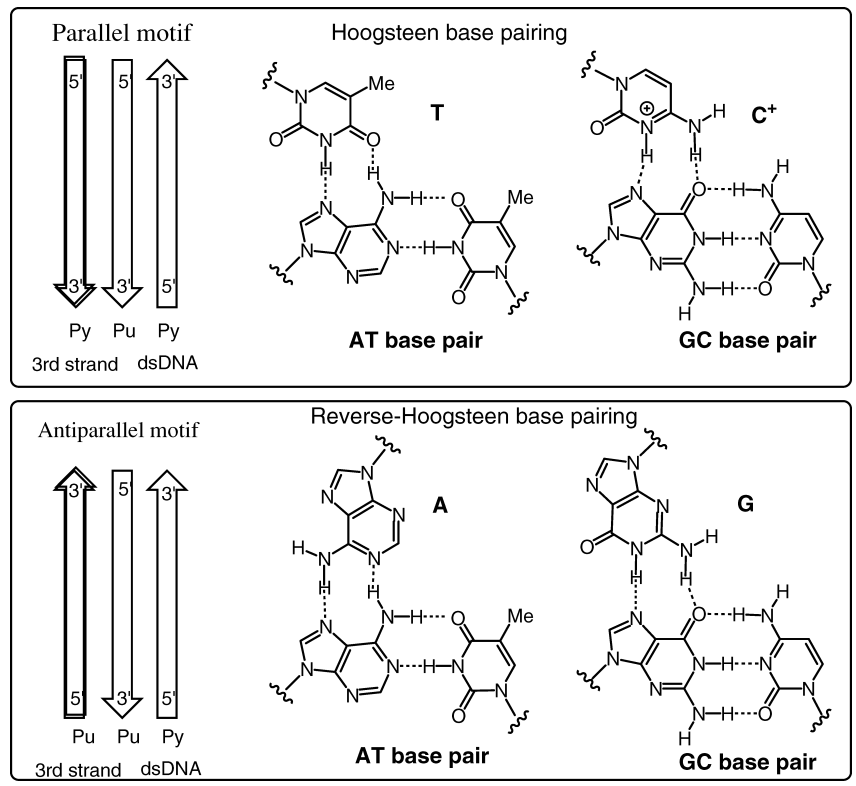

Fig. 6. Schematic and Simplified Drawings of Parallel and Antiparallel Motif Triplexes (Left), and Structures of Hoogsteen and Reverse-HoogsteenType Base Triads (Right)

a complicated high-ordered structure by itself due to the high content of the purine nucleobase. Of the two triplex motifs, we have focused on the parallel motif, in which problems could be overcome by an appropriate chemical modification of nucleic acids.

\section{Stabilization of the Parallel Motif Triplex}

As mentioned above, the parallel motif triplex has two significant limitations: relatively low stability of the triplex under physiological conditions and restriction of the target DNA sequence. Some efforts to improve the stability of the triplex structure are summarized below.

It is very important to know the exact three-dimensional structure of triplexes for the molecular design of chemically modified TFOs. Many studies on the structural analysis of the triplex have been reported; however, the strand conformations of a triplex depend on the method of structural analysis, the sequence of triplexes, and other conditions. Some data show that the strands in triplexes have an A-type helical structure, while other data support a B-type structure. ${ }^{36)}$ Thus the exact overall structures of triplexes are still unclear.

The structural difference between the duplexes consisting of RNA and DNA is well studied. ${ }^{4}$ Similarly, the stability of the triplexes formed from certain combinations of RNA and DNA strands was systematically evaluated, and it was found that the triplexes containing RNA as the third strand were generally more stable than that containing DNA as the third strand. ${ }^{37-41)}$ In addition, it was also observed that the $2^{\prime}-O$ Me derivative of RNA was able to form a stable triplex with target dsDNA. ${ }^{37,38)}$ These data confirm that the structural (or conformational) features of RNA promote stable triplex formation.

The group of Gryaznov et al. reported that oligonucleotide analogues, of which the phosphodiester linkage was replaced by an N3' $\rightarrow 5^{\prime}$ phosphoramidate linkage, showed high binding affinity with dsDNA (Fig. 7). ${ }^{42-45)}$ The oligonucleotide $\mathrm{N} 3^{\prime} \rightarrow 5^{\prime}$ phosphoramidate has a nitrogen atom at the $3^{\prime}$-posi- 
tion instead of an oxygen atom. This replacement results not only in a change in the property of the phosphodiester linkage but also in a change in the conformation of the sugar moiety. The less electron-withdrawing property of the nitrogen atom at the 3 '-position makes the sugar conformation the $\mathrm{N}$ type, ${ }^{46)}$ and this conformational change may result in enhanced triplex-forming ability.

On the other hand, we have evaluated the triplex-forming ability of $2^{\prime}, 4^{\prime}-\mathrm{BNA} / \mathrm{LNA}$, which has a methylene bridge between the $\mathrm{O}^{\prime}$ and $\mathrm{C}^{\prime}{ }^{\prime}$ atoms to restrict the sugar conformation in the $\mathrm{N}$ type. ${ }^{47-50)}$ The data from various experiments, such as UV melting experiments, ${ }^{47-49)}$ gel-retardation experiments, ${ }^{48,49)}$ and isothermal titration calorimetry (ITC) measurements, ${ }^{49,50)}$ showed that TFOs containing $2^{\prime}, 4^{\prime}$ BNA/LNA monomers formed extremely stable triplexes under physiological conditions. The UV melting experiments revealed that triplex formation by the $2^{\prime}, 4^{\prime}$-BNA/LNA oligonucleotides was sequence specific, ${ }^{47)}$ and the gel-retardation experiments indicated that the triplex containing the $2^{\prime}, 4^{\prime}$-BNA/LNA oligonucleotide as a third strand was more than 300 -fold more stable compared with the corresponding DNA triplex (Fig. 8) ${ }^{48)}$ In addition, it was observed that the TFO containing $2^{\prime}, 4^{\prime}$-BNA/LNA effectively inhibited the dsDNA-transcription factor interaction. ${ }^{48)}$ These results clearly indicate that restriction of the sugar conformation of TFOs to the $\mathrm{N}$ type is one promising strategy for stable triplex formation and, further, for an antigene technology to regulate gene expression at the transcription step. Very recently, detailed analysis of the effects of $2^{\prime}, 4^{\prime}$-BNA/LNA modifications on the triplex stability has been reported. ${ }^{51)}$ Moreover, the triplex-forming ability of ethylene-bridged nucleic acid (ENA), which has an ethylene bridge between the $\mathrm{O}^{\prime}$ and $\mathrm{C}^{\prime}$ ' atoms, was also evaluated. ${ }^{52)}$

In addition to the foregoing, various nucleic acid
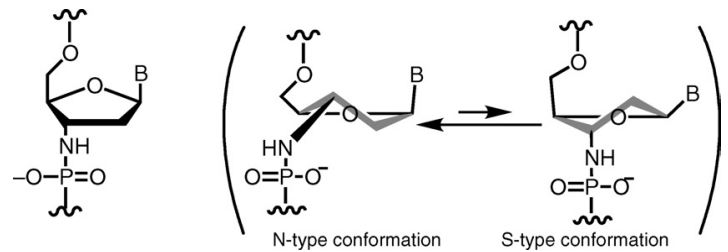

Fig. 7. Structure of $\mathrm{N}^{\prime} \rightarrow 5^{\prime}$ Phosphoramidate Oligonucleotide analogues, such as intercalator-tethered oligonucleotides ${ }^{53)}$ and $2^{\prime}$-aminoethoxy-DNA, ${ }^{54)}$ have been developed to stabilize triplex structure under physiological conditions.

\section{Extension of Target Sequence in the Parallel Motif Triplex}

In the parallel motif triplex, the adenine nucleobase in the AT base pair and guanine in the GC pair can be recognized by thymine and cytosine nucleobases, respectively, via Hoogsteen hydrogen bondings. ${ }^{36)}$ However, it is difficult to recognize thymine in the TA base pair and cytosine in the CG base pair by triplex formation. ${ }^{36)}$ To overcome this problem, many nucleobase analogues have been synthesized to date. ${ }^{55}$ A nucleoside analogue with a phenylimidazole derivative $\left(\mathrm{D}_{3}\right)$ was developed by the group of Dervan et al. (Fig. 9). $\left.{ }^{56}\right)$ The $\mathrm{D}_{3}$ was designed to recognize the shape of the PyPu base pair in the major groove. The TFO containing $\mathrm{D}_{3}$ recognized the $\mathrm{PyPu}$ interruption in the homopurine-homopyrimidine sequence and formed a stable triplex. However, it was not obvious how $\mathrm{D}_{3}$ recognizes the PyPu base pairs. A subsequent study showed that $\mathrm{D}_{3}$ did not recognize the edge of the $\mathrm{PyPu}$ base pairs but worked as an intercalator. ${ }^{57)}$ Based on these results, a novel nucleobase analogue (S) for exact recognition of a TA base pair was reported by Guianvarc'h et al. (Fig. 9) ${ }^{58)}$ The hydrogen bonding scheme between $\mathrm{S}$ and the TA base pair was proposed. Recently, another analogue $\left(\mathrm{B}^{\mathrm{t}}\right)$ was prepared by the same group, and its TA recognition ability was also evaluated (Fig. 9). ${ }^{59)}$

On the other hand, some nucleobase analogues with simpler chemical structures have been employed for recognition of a CG base pair. Prévot-Halter and Leumann reported that the novel thymine nucleobase analogue ${ }^{4 \mathrm{H}} \mathrm{T}$ (Fig. 10), which lacks a carbonyl oxygen at the 4-position, effectively recognized a CG base pair. ${ }^{60}$ This result included two possibilities for hydrogen bonding between ${ }^{4 \mathrm{H}} \mathrm{T}$ and a $\mathrm{CG}$ base pair: 1) the $\mathrm{N} 3$ atom in ${ }^{4 \mathrm{H}} \mathrm{T}$ and the 4 -amino group in $\mathrm{C}$ and 2) the $\mathrm{O} 2$ atom in ${ }^{4 \mathrm{H}} \mathrm{T}$ and the 4-amino group in $\mathrm{C}$. We independently observed that $\mathrm{T}$ and $\mathrm{C}$ nucleobases in the third strand were able to interact with a CG base pair in dsDNA. ${ }^{47)}$ This result indicates that the $\mathrm{O} 2$ atom in Py nucleobases plays an important role in the recognition of a CG base pair. To clarify this point, we selected 2-pyridone $(\mathrm{P})$ as a nucleobase (Fig. 10). ${ }^{61-63)}$ The homopyrimidine TFO containing P suc-

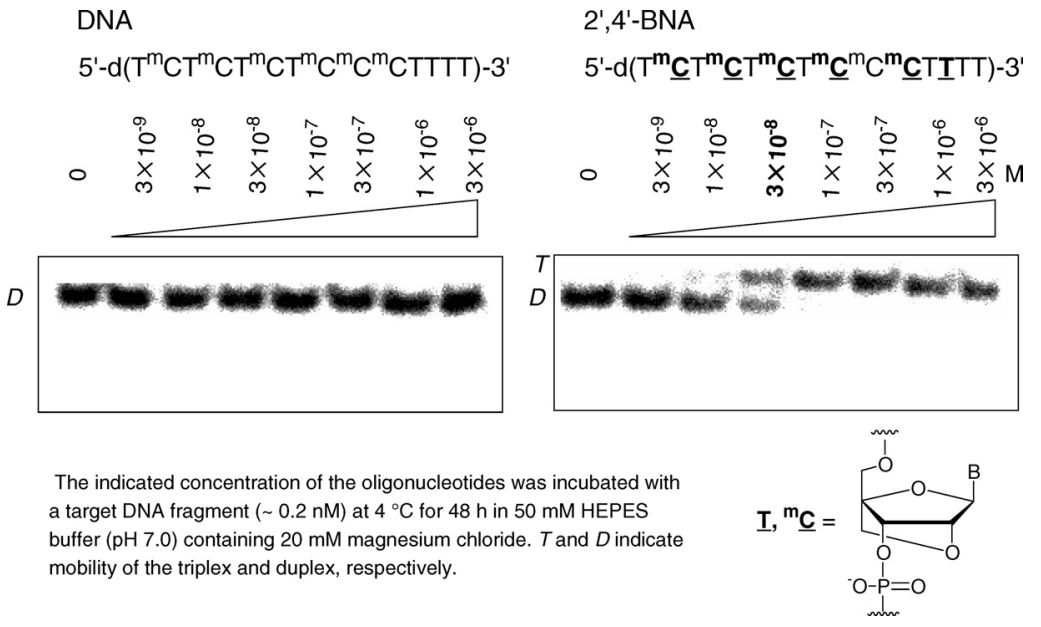

Fig. 8. Gel-Retardation Experiments Showing Significant Binding Affinity of the $2^{\prime}, 4^{\prime}$-BNA Modified TFO to the Target dsDNA 
<smiles>O=C(Nc1cccc(-c2cn(C3CC(O)C(CO)O3)cn2)c1)c1ccccc1</smiles><smiles>O=C(O)Nc1nc(-c2cccc(NC(=O)CC3CC(O)C(CO)O3)c2)cs1</smiles><smiles>CNc1ncc(-c2ccc3nc(C4C[C@H](O)[C@@H](CO)O4)[nH]c3c2)s1</smiles>

Fig. 9. Structures of the Nucleoside Analogues to Recognize TA Interruption

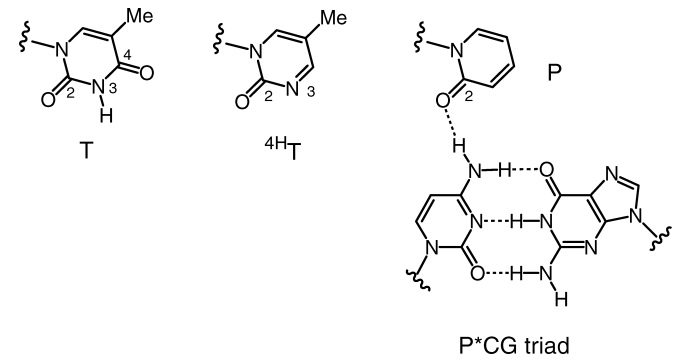

Fig. 10. Structures of the $\mathrm{T},{ }^{4 \mathrm{H}} \mathrm{T}$, and $\mathrm{P} * \mathrm{CG}$ Triad

cessfully recognized a CG base pair in a homopurine-homopyrimidine dsDNA and formed a triplex structure, which means that the $\mathrm{O} 2$ atom in $\mathrm{T}, \mathrm{C}$, or ${ }^{4 \mathrm{H}} \mathrm{T}$ form a hydrogen bond with the 4-amino group of $\mathrm{C}$ in a $\mathrm{CG}$ base pair. Thus the simple nucleobase $\mathrm{P}$ effectively recognized a $\mathrm{CG}$ base pair; however, the stability of the $\mathrm{P} * \mathrm{CG}$ triad was insufficient. Next, we introduced the $\mathrm{P}$ nucleobase into the $2^{\prime}, 4^{\prime}$ BNA/LNA structure to improve the stability of the triplex including the $\mathrm{P} * \mathrm{CG}$ triad. As expected, the TFO containing the $2^{\prime}, 4^{\prime}$-BNA-P monomer formed a stable triplex with a homopurine-homopyrimidine dsDNA including a CG base pair (Fig. 11, Table 1) ${ }^{61-63)}$ Furthermore, a 15-mer TFO containing three $2^{\prime}, 4^{\prime}$-BNA-P monomers successfully hybridized with the corresponding DNA target that had three CG interruptions. ${ }^{62)}$ Thus a combination of the sugar modification to stabilize the triplex structure and the nucleobase modification to recognize a CG base pair works well and results in the desired nucleic acid analogue for the antigene strategy. Other 2-pyridone derivatives were also introduced into the $2^{\prime}, 4^{\prime}$-BNA/LNA structure, and the properties of these nucleoside analogues were evaluated. ${ }^{64,66)}$

As shown above, the importance of the combination of unnatural nucleobases and $2^{\prime}, 4^{\prime}-\mathrm{BNA} / \mathrm{LNA}$ is increasing. To prepare $2^{\prime}, 4^{\prime}$-BNA/LNA derivatives with a variety of unnatural nucleobases, we have successfully developed a synthetic route for the $\mathrm{C}$-nucleoside analogue of $2^{\prime}, 4^{\prime}$-BNA/LNA (Fig. 12). ${ }^{66,67)}$ This synthetic route involves a stereoselective coupling reaction between the aldehyde and the lithium or magnesium derivative of aromatic heterocycles, followed by

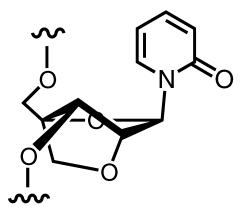

2', 4'-BNA-P

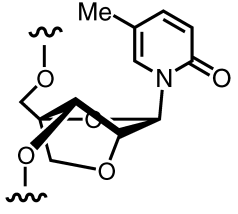

$2^{\prime}, 4^{\prime}-B N A-{ }^{m} P$

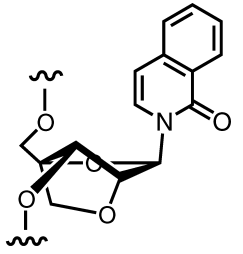

$2^{\prime}, 4^{\prime}-B N A-{ }^{i} Q$
Fig. 11. Structures of $2^{\prime}, 4^{\prime}$-BNA-P and Its Derivatives

Table 1. $T_{\mathrm{m}}$ Values $\left({ }^{\circ} \mathrm{C}\right)$ of the Triplexes Comprising Modified TFOs

$5^{\prime}-\mathrm{TTTTT}^{\mathrm{m}} \mathrm{CTXT}^{\mathrm{m}} \mathrm{CT}^{\mathrm{m}} \mathrm{CT}^{\mathrm{m}} \mathrm{CT}-3^{\prime}$

5'-GCTAAAAAGAYAGAGAGATCG-3'

3'-CGATTTTTCTZTCTCTCTAGC-5'

\begin{tabular}{ccccc}
\hline \hline X & \multicolumn{5}{c}{ YZ } \\
\cline { 2 - 5 } & CG & GC & TA & AT \\
\hline $2^{\prime}, 4^{\prime}$-BNA-P & 33 & 19 & 14 & 23 \\
$2^{\prime}, 4^{\prime}$-BNA- ${ }^{-} \mathrm{P}$ & 32 & 21 & 14 & 23 \\
$2^{\prime}, 4^{\prime}$-BNA-'Q & 29 & 20 & 16 & 15 \\
P & 24 & 16 & 15 & 15 \\
T & 25 & 20 & 17 & 44 \\
\hline
\end{tabular}

Conditions: $140 \mathrm{~mm} \mathrm{KCl}, 10 \mathrm{~mm} \mathrm{MgCl}, 7 \mathrm{~mm} \mathrm{Na}_{2} \mathrm{HPO}_{4}$ buffer (pH 7.0).

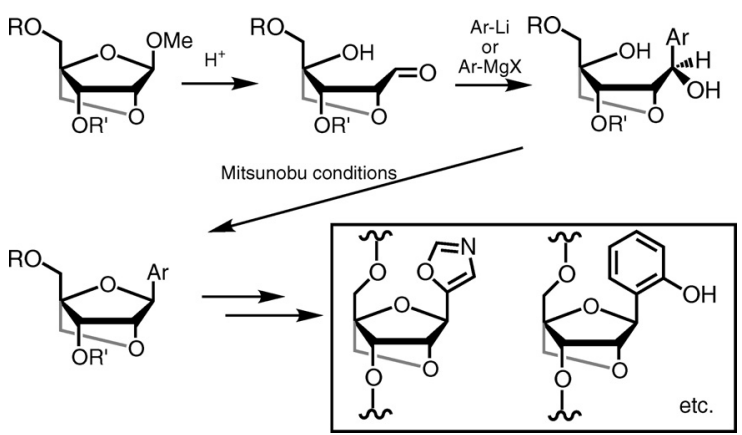

Fig. 12. Synthetic Route for the C-Nucleoside Analogues of 2',4'BNA/LNA

a ring-closure reaction using Mitsunobu conditions. Using this synthetic scheme, various $\mathrm{C}$-nucleoside derivatives of $2^{\prime}, 4^{\prime}$-BNA/LNA have been synthesized. ${ }^{6-68)}$ Very recently, we have succeeded in preparing the $2^{\prime}, 4^{\prime}$-BNA/LNA analogues bearing phenols as a nucleobase to recognize a TA or UA interruption in a homopurine-homopyrimidine DNA sequence (Fig. 13). ${ }^{69,70)}$

\section{Conclusion}

Based on the concept of "preorganization of the nucleic acid conformation in a suitable form by a bridged structure," we have developed a variety of BNAs. Among these BNAs, 2',4'-BNA/LNA showed significant hybridization ability to its dsDNA target under physiological conditions. A combination of unnatural nucleobases and the $2^{\prime}, 4^{\prime}$-BNA/LNA structure effectively functioned and recognized $\mathrm{PyPu}$ interruptions in a homopurine-homopyrimidine DNA sequence. Thus $2^{\prime}, 4^{\prime}$-BNA/LNA is a promising candidate for a practical antigene molecule. Applications of $2^{\prime}, 4^{\prime}$-BNA and other BNA families to various post-genome technologies are now in progress. 
Acknowledgments I am very grateful to Professor Takeshi Imanishi of Osaka University Graduate School of Pharmaceutical Sciences, Osaka University, for his valuable advice and discussions. I also thank my collaborators in our laboratory. Part of this work was supported by a Grant-in-Aid from the Ministry of Education, Culture, Sports, Science, and Technology, Japan, a Grant for Research on Health Sciences focusing on Drug Innovation from the Japan Health Sciences Foundation, Industrial Technology Research Grant Program from the New Energy and Industrial Technology Development Organization (NEDO) of Japan, and the Japan Securities Scholarship Foundation (JSSF) Academic Research Grant Program.

\section{References}

1) Buchini S., Leumann C. J., Curr. Opin. Chem. Biol., 7, 717-726 (2003).

2) Mapp A. K., Org. Biomol. Chem., 1, 2217-2220 (2003).

3) Seidman M. M., Glazer P. M., J. Clin. Invest., 112, 487-494 (2003).

4) Saenger W., "Principles of Nucleic Acid Structure," Springer-Verlag, New York, 1984.

5) Herdewijn P., Liebigs Ann. Chem., 1996, 1337-1348 (1996).

6) Kool E. T., Chem. Rev., 97, 1473-1487 (1997).

7) Tarköy M., Bolli M., Schweizer B., Leumann C., Helv. Chim. Acta, 76, 481-510 (1993)

8) Tarköy M., Bolli M., Leumann C., Helv. Chim. Acta, 77, 716-744 (1994).

9) Bolli M., Leumann C., Angew. Chem., Int. Ed. Engl., 34, 694-696 (1995).

10) Imanishi T., Obika S., J. Syn. Org. Chem. Jpn., 57, 969-980 (1999).

11) Obika S., Yakugaku Zasshi, 120, 147-158 (2000).

12) Imanishi T., Obika S., Chem. Commun., 2002, 1653-1659 (2002).

13) Obika S., Nanbu D., Hari Y., Morio K., In Y., Ishida T., Imanishi T., Tetrahedron Lett., 38, 8735-8738 (1997).

14) Obika S., Nanbu D., Hari Y., Andoh J., Morio K., Doi T., Imanishi T., Tetrahedron Lett., 39, 5401-5404 (1998).

15) Obika S., Morio K., Nanbu D., Imanishi T., Chem. Commun., 1997, 1643 -1644 (1997).

16) Obika S., Morio K., Hari Y., Imanishi T., Bioorg. Med. Chem. Lett., 9, 515-518 (1999)

17) Obika S., Morio K., Hari Y., Imanishi T., Chem. Commun., 1999, 2423-2424 (1999).

18) Obika S., Morio K., Nanbu D., Hari Y., Itoh H., Imanishi T., Tetrahedron, 58, 3039-3049 (2002)

19) Obika S., Andoh J., Onoda M., Nakagawa O., Hiroto A., Sugimoto T. Imanishi T., Tetrahedron Lett., 44, 5267-5270 (2003).

20) Obika S., Sekiguchi M., Osaki T., Shibata N., Masaki M., Hari Y., Imanishi T., Tetrahedron Lett., 43, 4365-4368 (2002).

21) Obika S., Osaki T., Sekiguchi M., Somjing R., Harada Y., Imanishi T., Tetrahedron Lett., 45, 4801-4804 (2004).

22) Obika S., Andoh J., Sugimoto T., Miyashita K., Imanishi T., Tetrahedron Lett., 40, 6465-6468 (1999).

23) Obika S., Onoda M., Morita K., Andoh J., Koizumi M., Imanishi T., Chem. Commun., 2001, 1992-1993 (2001).

24) Obika S., Nakagawa O., Hiroto A., Hari Y., Imanishi T., Chem. Commun., 2003, 2202-2203 (2003).

25) Singh S. K., Nielsen P., Koshkin A. A., Wengel J., Chem. Commun., 1998, 455-456 (1998)

26) Koshkin A. A., Singh S. K., Nielsen P., Rajwanshi V. K., Kumar R., Meldgaard M., Olsen C. E., Wengel J., Tetrahedron, 54, 3607-3630 (1998).

27) Wengel J., Accounts Chem. Res., 32, 301-310 (1999).

28) Orum H., Wengel J., Curr. Opin. Mol. Ther., 3, 239-243 (2001).

29) Petersen M., Wengel J., Trends Biotechnol., 21, 74-81 (2003).

30) http://www.proligo.com

31) Braasch D. A., Corey D. R., Chem. Biol., 8, 1-7 (2001).

32) Felsenfeld G., Davies D. R., Rich A., J. Am. Chem. Soc., 79, 2023 2024 (1957).

33) Felsenfeld G., Rich A., Biochim. Biophys. Acta, 26, 457-468 (1957).

34) Hoogsteen K., Acta Crystallogr., 12, 822-823 (1959).

35) Hoogsteen K., Acta Crystallogr., 16, 907-916 (1963).
36) Soyfer V. N., Potaman V. N, "Triple-Helical Nucleic Acids," SpringerVerlag, New York, 1995.

37) Escudé C., Sun J. S., Rougée M., Garestier T., Hélène C., Acad. Sci., Ser. III, 315, 521-525 (1992).

38) Escudé C., François J. S., Sun J. S., Ott G., Sprizl M., Garestier T., Hélène C., Nucleic Acids Res., 21, 5547—5553 (1993).

39) Roberts R. W., Crothers D. M., Science, 258, 1463-1466 (1992).

40) Wang S., Kool E. T., Biochemistry, 34, 4125-4132 (1995).

41) Han H., Dervan P. B., Proc. Natl. Acad. Sci. U.S.A., 90, 3806-3810 (1993).

42) Gryaznov S., Chen J.-K., J. Am. Chem. Soc., 116, $3143-3144$ (1994).

43) Gryaznov S. M., Lloyd D. H., Chen J.-K., Schultz R. G., DeDionisio L. A., Ratmeyer L., Wilson W. D., Proc. Natl. Acad. Sci. U.S.A., 92, 5798-5802 (1995).

44) Escudé C., Giovannangeli C., Sun J. S., Lloyd D. H., Chen J. K., Gryaznov S. M., Garestier T., Hélène C., Proc. Natl. Acad. Sci. U.S.A., 93, 4365-4369 (1996).

45) Gryaznov S. M., Biochim. Biophys. Acta, 1489, 131-140 (1999).

46) Tereshko V., Gryaznov S., Egli M., J. Am. Chem. Soc., 120, 269-283 (1998).

47) Obika S., Hari Y., Sugimoto T., Sekiguchi M., Imanishi T., Tetrahedron Lett., 41, 8923-8927 (2000).

48) Obika S., Uneda T., Sugimoto T., Nanbu D., Minami T., Doi T., Imanishi T., Bioorg. Med. Chem., 9, 1001-1011 (2001).

49) Torigoe H., Hari Y., Sekiguchi M., Obika S., Imanishi T., J. Biol. Chem., 276, 2354-2360 (2001).

50) Torigoe H., Obika S., Imanishi T., Nucleosides Nucleotides Nucleic Acids, 20, 1235-1238 (2001).

51) Sun B. W., Babu B. R., Sorensen M. D., Zakrzewska K., Wengel J., Sun J. S., Biochemistry, 43, 4160-4169 (2004).

52) Koizumi M., Morita K., Daigo M., Tsutsumi S., Abe K., Obika S., Imanishi T., Nucleic Acids Res., 31, 3267-3273 (2003).

53) Asseline U., Thuong N. T., Hélène C., New J. Chem., 21, 5-17 (1997).

54) Cuenoud B., Casset F., Hüsken D., Natt F., Wolf R. M., Altmann K.H., Martin P., Moser H. E., Angew. Chem., Int. Ed. Engl., 37, 12881291 (1998).

55) Luyten I., Herdewijn P., Eur. J. Med. Chem., 33, 515-576 (1998).

56) Griffin L. C., Kiessling L. L., Beal P. A., Gillespie P., Dervan P. B., J. Am. Chem. Soc., 114, 7976-7982 (1992).

57) Koshlap K. M., Gillespie P., Dervan P. B., Feigon J., J. Am. Chem. Soc., 115, 7908-7909 (1993).

58) Guianvarc'h D., Benhida R., Fourrey J.-L., Maurisse R., Sun J.-S., Chem. Commun., 2001, 1814-1815 (2001).

59) Guianvarc'h D., Fourrey J.-L., Maurisse R., Sun J.-S., Benhida R., Org. Lett., 4, 4209-4212(2002).

60) Prévot-Halter I., Leumann C. J., Bioorg. Med. Chem. Lett., 9, 2657 2660 (1999).

61) Obika S., Hari Y., Sekiguchi M., Imanishi T., Angew. Chem., Int. Ed. Engl., 40, 2079-2081 (2001).

62) Obika S., Hari Y., Sekiguchi M., Imanishi T., Chem. Eur. J., 8, 47964802 (2002).

63) Torigoe H., Hari Y., Obika S., Imanishi T., Nucleosides Nucleotides Nucleic Acids, 22, 1097-1099 (2003).

64) Hari Y., Obika S., Sekiguchi M., Imanishi T., Tetrahedron, 59, 5123 5128 (2003).

65) Torigoe H., Hari Y., Obika S., Imanishi T., Nucleosides Nucleotides Nucleic Acids, 22, 1571-1573 (2003).

66) Obika S., Hari Y., Morio K., Imanishi T., Tetrahedron Lett., 41, 215219 (2000).

67) Hari Y., Obika S., Sakaki M., Morio K., Yamagata Y., Imanishi T., Tetrahedron, 58, 3051-3063 (2002).

68) Obika S., Hari Y., Morio K., Imanishi T., Tetrahedron Lett., 41, 221224 (2000).

69) Obika S., Hari Y., Inohara H., Imanishi T., Nucleic Acids Res. Suppl., 1, 171-172 (2001).

70) Inohara H., Obika S., Imanishi T., Nucleic Acids Res. Suppl., 4, 63-64 (2004). 